\title{
Immediate Effect of Eye Movement on Static Balance according to Age in Elderly Individuals
}

\author{
Seung-Hee Seo, Hwi-Bin Bae, Yea-Jin Cho, Young-Sook Bae \\ Department of Physical Therapy, College of Health Science, Gachon University, Incheon, Korea
}

Purpose: This study investigated changes in static balance during eye movement while in an upright standing position and compared static balance in elderly individuals according to age.

Methods: A total of 154 elderly persons (male 23, female 136) were enrolled in the study. Participants followed an eye movement program that consisted of randomly occurring pursuit eye movement and saccadic eye movement. Participants were asked to remain in the double-leg standing position for 2 minutes 30 second while fixating their eyes on a specific target, after which they were instructed to perform eye movements for 2 minutes and 30 seconds. Static balance was measured in terms of the area, length, and average speed (cm/ s) of the center of pressure (COP) displacement before and after eye movement intervention with the eyes open.

Results: The area, length, and velocity of COP displacement improved significantly $(p<0.01)$ after intervention. No significant differences among age groups were observed.

Conclusion: The results indicated that eye movement was an effective intervention for improving static balance in elderly persons.

Keywords: Eye movement, Static balance, Elderly

\section{서 론}

균형은 일상생활의 모든 동적 수행에 중요한 영향을 주며 신체를 평 형상태로 유지시키는 능력이다. 이는 안정성과 운동성이 조화를 이 룬 역동적인 현상으로, 균형을 유지하는 것은 시각계, 전정계, 청각계, 체감각계, 운동계를 포함하는 복잡한 과정이라 할 수 있다. ${ }^{12}$ 나이가 들어감에 따라 직립자세에서 자세동요(body sway)가 증가되며, ${ }^{3}$ 이로 인하여 노인은 서있는 자세에서 자세조절 능력이 저하가 되며, 이는 낙상의 주된 원인이 될 수 있다. 노인의 낙상위험요인은 균형감각과 밀접한 관련이 있으며, 노인은 다리와 발바닥의 감각 정보의 정확도 가 감소되며 이로 인한 자세 안정성이 저하될 수 있다. ${ }^{4}$ 그러므로 노 인은 균형을 유지하는 것이 어려울 수 있으며, 서 있는 자세에서 균형 을 유지하기 위해 시각이 우세하고 중요한 요인으로 작용하게 된다. 특히 노인에서 시각 기능(visual function)은 균형과 독립적인 일상생 활 수행 능력과 관련 있다.6

인간은 주변환경을 확인하고 시각자극(visual stimuli)에 반응하기 위해서는 수의적 또는 비수의적인 추적 안구운동(pursuit eye move-

Received Sep 12, 2016 Revised Oct 11, 2016

Accepted Oct 24, 2016

Corresponding author Young-Sook Bae

E-mail baeys@gachon.ac.kr ment)와 단속 안구운동(saccadic eye movement)이 유발된다. 안구운 동은 단속, 부드러운 추적, 그리고 눈 모음(convergence)으로 물체를 주시하도록 하여 안구운동을 유발한다. 추적 안구운동은 움직이는 물체를 따라 안구를 움직이는 것이며, 단속 안구운동은 두 지점 사 이를 두 눈이 같은 방향으로 빠르게 동시에 움직이는 것이다. ${ }^{8}$

Lee 등9은 또한 시각 되먹임을 이용한 머리조절 훈련이 뇌졸중 환 자의 균형과 보행을 증진시킨다고 하였다. 또한 스쿼트 동작을 수행 할 때 체간과 하지의 움직임에 영향을 미친다. ${ }^{10} \mathrm{Im}^{11}$ 은 추적 안구훈련 을 수행한 아이스하키 선수들은 안구운동의 수행능력이 우수할수 록 운동수행능력이 우수하다고 하였다. Stoffregen 등'2은 안구 단속 운동을 수행한 후 눈을 뜨고 감은 상태에서 머리와 체간 동요가 변한 다는 것을 확인하였고, 특히 젊은 성인에서 움직이지 않는 물체에 시 선을 고정한 상태와 비교하여 단속 안구운동이 수행될 때 자세동요 가 감소되었다. 이처럼 최근 연구에서는 안구운동이 자세조절(postural control)과 움직임 수행에 영향을 미치는 요인임을 확인하였다. 따라서 이러한 보고는 서 있는 자세에서 균형을 조절하는 능력이 저 하될 수 있고, 연령이 증가될수록 균형능력이 저하될 수 있는 노인에 
서는 안구운동은 중요한 요소라 할 수 있을 것이다. 이와 같이 여러 연구에서 시각자극과 안구운동이 균형능력에 대한 효과에 대하여 소개되고 있지만, 노인들의 연령별 안구운동 수행과 균형능력에 대 한 연구는 미흡한 실정이다. 이에 본 연구에서는 이전 연구를 고려하 여, ${ }^{12,13}$ 건강한 노인에게 서 있는 자세에서 안구운동을 적용하였을 때 연령별(65-74세 그룹: young older, 75-84세 그룹: middle older, 85세 이 상: old older)로 즉각적인 정적 균형능력의 변화를 확인하는 것이 목 적이다.

\section{연구 방법}

\section{1. 연구대상}

본 연구의 대상자는 인천시 4 개의 노인복지센터에 부착된 포스터를 통하여 자발적으로 연구 참여에 동의한 자로 하였다. 대상자의 선정 기준은 독립적 보행이 가능한 65 세 이상의 노인으로 낙상과 어지러 움의 경험이 없고, 5 분 이상 안구운동의 중재를 수행할 수 있는 자로 하였다. 제외기준은 하지에 외과적 수술병력이 있고, 균형능력에 문 제를 유발시키는 약물을 복용하며, 안구운동을 수행하는 동안 어지 러움을 느끼거나 불편함을 호소하는 것처럼 연구절차 중 수행능력 에 문제가 유발되는 자로 하였다.

\section{2. 연구도구}

1) 정적 균형능력 분석장비

안구운동을 수행 전과 후 대상자의 정적 균형을 측정하기 위하여 BioRescue (RM Ingenierie, Rodez, France)를 사용하였다. BioRescue는 발판(Platform), 소프트웨어와 모니터로 구성되어 있다. 발판 $(610 \mathrm{~mm}$ $\times 580 \mathrm{~mm} \times 10 \mathrm{~mm})$ 은 $4 \mathrm{~mm}$ 로 매우 얇고, 1,600여 개의 압력센서가 내장되어 있다. 발판은 접촉하고 있는 양 발의 중력중심점(center of pressure, $\mathrm{COP}$ )의 이동과 면적을 안전하고 정확하게 측정하며, 측정된 데이터를 컴퓨터의 소프트웨어로 전송하는 장비이다. 발판에서 측정 된 데이터는 서있는 자세에서 균형을 유지하는 동안의 COP가 움직 이는 궤적(trajectory)을 시각화하여 모니터에서 나타내며, 측정결과 를 모니터에 대상자의 $\mathrm{COP}$ 궤적의 면적, $\mathrm{COP}$ 궤적의 이동거리와 $\mathrm{COP}$ 궤적의 속도를 양적 능력으로 객관화된 수치로 보여준다.

정적 균형은 전통적으로 가만히 서있는 동안 동안 $\mathrm{COP}$ 의 변화와 관련된 움직임으로 평가한다. 따라서 정적 균형은 눈을 뜬 상태에서 안구운동을 수행하기 전과 후에 $\mathrm{COP}$ 의 면적 $\left(\mathrm{mm}^{2}\right), \mathrm{COP}$ 의 이동거리 $(\mathrm{cm})$ 그리고 $\mathrm{COP}$ 의 평균속도 $(\mathrm{cm} / \mathrm{s})$ 로 측정하였다.

\section{2) 안구운동 중재}

대상자는 맨발로 BioRescue의 발판 중간 부위에 두발의 각도는 $30^{\circ}$,
두발의 발뒤꿈치 간격은 $9 \mathrm{~cm}$ 가 되게 한 상태로 서있게 하였다. 이때 팔은 체간 옆에 편안한 상태로 두게 하였다. 그 후 $3 \mathrm{~m}$ 전방에 위치한 모니터(1,100 mm×648 mm, Samsung, LT24E395KD) 화면에 나타나는 둥근 점(target)이 움직이는 대로 체간과 머리는 움직이지 않고 안구 만 움직이게 하여 안구운동을 수행하게 하였다. 모니터의 바탕은 흰 색이며 화면에 나타나는 점은 검은색으로 직경은 $2 \mathrm{~cm}$ 이다. 점은 소 프트웨어 플래시(software Flash)로 나타나게 하고, LCD monitor 화면 에 나타나게 하였다.

안구운동은 추적안구운동과 단속안구운동을 무작위로 나타나 게 하였다. 대상자가 BiosRescue 발판 위에 서게 한 후 모니터 화면 중 간에 있는 둥근 점이 움직이지 않는 상태로 약 2 분 30 초 정도 고정시 켜서 대상자의 시선이 한 곳에 집중되게 한다. 30초간 휴식을 취하게 한다. 그 후 둥근 점이 모니터 화면의 한 곳에 나타난 후 사라지고 즉 시 다른 위치에서 나타나게 하여, 대상자가 점을 따라 안구를 움직이 게 하는 단속안구운동과 지속적으로 움직이는 점을 따라 안구를 움 직이게 하는 추적 안구운동을 2 분 30 초 동안 수행하게 하였다. 둥근 점이 나타나고 움직이는 주기는 $0.5 \mathrm{~Hz}$ 이고, 모니터 화면의 수평과수 직방향에서 무작위로 나타나게 하고 움직이게 설정하였다.

대상자가 안구운동 중재를 수행하는 동안 머리의 움직임을 피하 기 위하여 이전 연구를 고려하여 왼쪽과 오른쪽, 양쪽의 전체 거리는 시야가 약 11 도가 되게 하였다. ${ }^{12}$

\section{3. 연구절차}

본 연구의 선정기준에 맞는 대상자들을 일대일 면담을 통하여 일반 적 특성을 수집하였고, 모든 대상자에게 연구를 수행하기 전에 추적 안구운동과 단속안구운동에 대해 교육하였다. 교육 후 맨발로 BioRescue 발판 위에 눈을 뜬 상태로 서있게 한 상태에서 $3 \mathrm{~m}$ 전방의 모 니터 화면에 있는 점을 1 분 동안 주시하도록 하게 하였고, 이 때 연구 전 정적 균형을 측정하였다. 대상자가 BioRescue 발판 위에 서 있는 상 태에서 추적안구운동과 단속안구운동으로 구성된 안구운동 프로 그램을 수행하기 위하여 모니터 화면에 있는 점을 추적 또는 단속으 로 움직이게 하였다. 안구운동은 5 분간 적용하였다. 안구운동이 끝 나는 즉시 정적 균형을 다시 측정하였다. 안구운동 중재를 적용하는 시간은 10 명의 예비연구를 통하여 대상자가 어지럽거나 불편함을 느 끼지 않는 정도의 시간인 5 분으로 정하였다. 본 연구는 가천대학교 연구윤리위원회의 승인을 받아 연구를 수행하였다(1044396-201602HR-012-01).

\section{4. 자료분석}

본 연구에서 수집된 자료는 SPSS version 23.0 통계프로그램을 이용하 여 분석하였다. 대상자의 일반적 특성은 기술통계를 사용하였다. 중 
재전과 후의 연령별 그룹 간 종속변수의 변화는 One ANOVA로 비교 분석하였다. 모든 변수는 means \pm SEMs로 표시하였다. 효과크기(effect size, ES)는 $\mathrm{SS}_{\text {Between }} / \mathrm{SS}_{\mathrm{Tota}}$ 로 계산하였다. 통계학적 유의수준은 $\mathrm{p}<0.05$ 로 하였다.

\section{결 과}

전체 대상자 179명 중 연구를 끝까지 마치지 못한 20명을 제외한 159 명(남자 23, 여자 136)을 대상으로 하였다. 평균연령은 76.9세(범위 6586 years), 신장은 $152.6 \mathrm{~cm}$, 체중은 $58.3 \mathrm{~kg}$ 이었으며, 일반적 특성에 대 한 결과는 Table 1에 나타내었다.

연령에 따른 변화는 각 그룹 내 중재 전과 후의 COP 면적, 거리와 속도에서는 세 그룹 모두 매우 유의한 변화를 보였지만 $(\mathrm{p}<0.01)$, 그룹 간의 차이에서는 유의한차이는 없었다(Table 2).

\section{고 찰}

본 연구는 안구운동이 건강한 노인에게 서 있는 자세에서 안구운

Table 1. Baseline characteristics of the participants

\begin{tabular}{lrrrr}
\hline & $\begin{array}{c}\text { Young older } \\
(n=21)\end{array}$ & \multicolumn{1}{c}{$\begin{array}{c}\text { Middle older } \\
(n=105)\end{array}$} & $\begin{array}{c}\text { Old older } \\
(n=33)\end{array}$ & \multicolumn{1}{c}{$\begin{array}{c}\text { Total } \\
(n=159)\end{array}$} \\
\hline Age (year) & $67.26 \pm 2.03$ & $76.81 \pm 3.38$ & $85.88 \pm 1.20$ & $77.43 \pm 6.14$ \\
Height $(\mathrm{cm})$ & $156.75 \pm 7.16$ & $152.58 \pm 7.75$ & $150.00 \pm 6.80$ & $152.60 \pm 7.05$ \\
Weight $(\mathrm{kg})$ & $62.02 \pm 9.99$ & $58.38 \pm 7.75$ & $55.75 \pm 7.18$ & $58.32 \pm 8.11$ \\
\hline
\end{tabular}

Values are presented as Means \pm SD
동을 적용하였을 연령별(65-74세 그룹: young older, 75-84세 그룹: middle older, 85 세 이상: old older)에서 안구운동 시 정적 균형의 차이 를 확인한 결과, 안구운동 후 정적 균형은 증진되었지만, 연령에 따른 차이는 없었다.

어린 아이들은 안구를 움직이는 작업(task)을 수행하는 동안은 자 세동요가 감소될 수 있으며, ${ }^{14}$ Rougier와 $\mathrm{Ganin}^{15}$ 는 젊은 성인이 단속 안구운동을 수행하면 COG의 진폭이 감소된다고 하였고, 이는 직립 으로 서 있는 상태에서 자세를 유지하기 위한 자세조절의 기전을 변 경시킨다고 할 수 있다는 것이다. 안구의 외재근(extraocular muscle)의 근육이나 건 부분에 Ia 구심성 섬유(afferent fiber)를 활성화시키기에 충분한 기계적 진동을 적용하게 되면, 외재근이 이 신호를 지각(perception) 하게 되고, 이로 인하여 자세를 조절하는 중요한 요인으로 작 용하게 된다. ${ }^{16}$ 본 연구에서 노인의 연령별 그룹 모두에서 안구운동 후 COP 변위의 면적, 거리와 속도가 통계학적으로 매우 유의하게 감 소되었지만, 그룹 간 차이는 없었다. 이는 노인들도 젊은 사람과 유사 하게 추적운동을 수행할 수 있다고 보고한 것처럼, ${ }^{17}$ 연령의 증가는 안구운동에 영향을 주지 않는다는 의미로 해석할 수 있을 것이다. 따 라서 추적안구운동과 단속안구운동으로 구성된 안구운동 중재가 노인의 외재근을 활성화시키며, 이로 인하여 정적 자세의 균형을 증 진시키는 데 긍정적인 영향을 미쳤다고 할 수 있다.

간단한 과제를 수행할지라도, 앉아 있을 때보다 정적인 상태로 서 있을 때 집중력이 더 요구된다. ${ }^{18}$ 이러한 집중력은 신경학적 수준에서 집중력과 안구운동 과정이 해부학적인 부분에서 겹쳐지는 부분이 많아 깊은 연관성이 있다고 한다. ${ }^{19}$ 특히 수의적인 추적안구운동은 시각적 집중력에 중요한 기전으로 작용한다. ${ }^{20}$ 뇌졸중 환자에서도 보

Table 2. Comparisons of static balance between before and after intervention among the age

\begin{tabular}{|c|c|c|c|c|c|}
\hline & & Young older $(n=21)$ & Middle older $(n=105)$ & Old older $(n=33)$ & $\mathrm{p}$ \\
\hline \multirow[t]{5}{*}{ COP area $\left(\mathrm{mm}^{2}\right)$} & $\mathrm{Bl}$ & $55.52 \pm 15.58$ & $63.12 \pm 9.06$ & $106.19 \pm 13.06$ & \\
\hline & Al & $35.52 \pm 17.55$ & $33.12 \pm 5.96$ & $61.97 \pm 4.88$ & \\
\hline & Change & $-21.95 \pm 8.28$ & $-30.07 \pm 6.48$ & $-44.26 \pm 11.52$ & 0.352 \\
\hline & $(95 \% \mathrm{Cl})$ & $(-39.28 \sim-4.621)$ & $(-52.69 \sim-7.46)$ & $(-88.18 \sim-30.27)$ & \\
\hline & $p$ & 0.016 & 0.000 & 0.002 & \\
\hline \multirow[t]{5}{*}{ COP length $(\mathrm{cm})$} & $\mathrm{Bl}$ & $13.21 \pm 2.13$ & $13.24 \pm 0.62$ & $16.29 \pm 1.54$ & \\
\hline & $\mathrm{Al}$ & $9.85 \pm 1.20$ & $9.05 \pm 0.62$ & $10.77 \pm 0.93$ & \\
\hline & Change & $-3.67 \pm 0.42$ & $-4.19 \pm 0.45$ & $-5.52 \pm 0.10$ & 0.293 \\
\hline & $(95 \% \mathrm{Cl})$ & $(-4.24 \sim-2.89)$ & $(-5.07 \sim-3.30)$ & $(-7.78 \sim-3.27)$ & \\
\hline & $\mathrm{p}$ & 0.000 & 0.000 & 0.000 & \\
\hline \multirow[t]{5}{*}{ COP velocity $(\mathrm{cm} / \mathrm{sec})$} & $\mathrm{Bl}$ & $0.43 \pm 0.07$ & $0.44 \pm 0.22$ & $0.55 \pm 0.05$ & \\
\hline & $\mathrm{Al}$ & $0.33 \pm 0.06$ & $0.30 \pm 0.20$ & $0.37 \pm 0.03$ & \\
\hline & Change & $-0.10 \pm 0.01$ & $-0.13 \pm 0.02$ & $-0.18 \pm 0.039$ & 0.258 \\
\hline & $(95 \% \mathrm{Cl})$ & $(-0.133 \sim-0.08)$ & $(-0.18 \sim-0.99)$ & $(-0.26 \sim-0.10)$ & \\
\hline & $p$ & 0.002 & 0.000 & 0.000 & \\
\hline
\end{tabular}

Values are presented as Means $\pm \mathrm{SE}$.

$\mathrm{BI}$ : before intervention, Al: after intervention, COP: center of pressure. 
행 훈련 시 시각자극을 적용하였을 때 보행 능력과 보행 자신감이 증 진되었으며, ${ }^{21}$ 시각적 집중력이 뇌졸중 환자의 균형과 같은 기능 손상 그리고 낙상과도 상관성이 있다고 하였다. ${ }^{22} \mathrm{Huxhold}$ 등 23 은 집중력과 같은 인지적 요구와 자세조절 사이에는 연관성이 있다고 하였다. 본 연구에서는 안구운동을 추적안구운동과 단속안구운동을 무작위 로 수행하게 하였다. 그 결과, 자세 동요가 감소됨을 보였다. 이는 물체 를 따라 안구를 움직이는 운동이 노인들의 집중력을 증가시키고 이 로 인하여 정적 균형에 긍정적인 효과가 나타난 것이라고 저자는 예 측하는 바이다.

본 연구결과에서 연구 전 연령별 대상자의 나이가 증가될수록 $\mathrm{COP}$ 의 이동 면적, 거리와 속도가 증가됨이 확인되었다. 이러한 결과 는 노화가 진행되어 시각적 집중력이 손상되거나 또는 시각 처리시간 이 느려지게 되면 균형이 요구되는 이동수행능력의 저하와 관련이 있 을 수 있다. ${ }^{24}$ 그러나 안구운동 후 $\mathrm{COP}$ 의 이동 면적, 거리와 속도가 세 그룹 모두에서 유의한 차이를 보이며 증가함을 보였으나, 그룹간의 차 이는 없었다. 이전 연구에서 젊은이에게 추적안구운동과 단속안구운 동이 자세동요를 감소시키며, ${ }^{25}$ 성인에서 시각자극이 균형능력에 영 향을 미친다고 하였다. ${ }^{26}$ 그러므로 연령이나 노화와 상관없이 안구운 동이 자세 조절에 긍정적인 작용을 하는 요인이라고 할 수 있다.

이상에서 살펴본 바와 같이 안구운동이 서있는 상태에서 정적 균 형이 증진된다는 것을 확인하였으며, 이는 안구운동이 균형능력을 증진시키는 데 효과적인 방법이라 생각할 수 있다. 그러나 본 연구는 안구운동을 5 분이라는 짧은 시간에 수행된 단기효과(short-term ef$\mathrm{fect}$ 를 확인한 것이므로, 장기적인 효과에 대해서는 명확하지 않을 수 있다. 또한 낙상의 경험이 없고 균형능력에 문제가 없는 노인을 대 상으로 하였기에, 이를 균형능력이 저하된 노인이나 균형능력과 관련 된 환자에게 적용하기에는 제한이 있을 것이라 생각된다. 향후 이러 한 제한점을 보완한 연구가 필요하리라 생각된다. 또한 서 있는 상태 에서 자세를 조절을 하기 위해 하지 근육이 활성화되며, ${ }^{27}$ 무릎관절 이 자세조절에 영향을 미칠 수 있다. ${ }^{28}$ 따라서 저자는 앞으로의 연구 에 안구운동에 따른 균형과 하지 근육의 활성화에 대한 변화에 대한 연구도 수행할 계획이다.

\section{Acknowledgements}

본 연구는 교육부의 대학특성화(CK)사업 사업비를 받아 진행된 것입니다(NRF-2014H1C9A2A02024284).

\section{참고문헌}

1. Cohen H, Blatchly CA, Gombash LL. A study of the clinical test of sen- sory interaction and balance. Phys Ther. 1993;73(6):346-51.

2. Kisner C, Colby LA. Therapeutic exercise: Foundations and techniques. Fa Davis, 2012

3. Fernie G, Gryfe C, Holliday P et al. The relationship of postural sway in standing to the incidence of falls in geriatric subjects. Age Ageing. 1982;11(1):11-6.

4. Stelmach GE, Worringham CJ. Sensorimotor deficits related to postural stability. Implications for falling in the elderly. Clin Geriatr Med. 1985; 1(3):679-94.

5. Chen EW, Fu AS, Chan K et al. Balance control in very old adults with and without visual impairment. Eur J App Physiol. 2012;112(5):1631-6.

6. Aartolahti E, Häkkinen A, Lönnroos E et al. Relationship between functional vision and balance and mobility performance in communitydwelling older adults. Aging Clin Exp Res. 2013;25(5):545-52.

7. Krauzlis RJ. The control of voluntary eye movements: New perspectives. Neuroscientist. 2005;11(2):124-37.

8 . Rashbass C. The relationship between saccadic and smooth tracking eye movements. J Physiol. 1961;159(2):326-38.

9. Lee KS, Choe HS, Lee JH. Influence of visual feedback training on the balance and walking in stroke patients. J Kor Phys Ther. 2015;27(6):40712.

10. hee Bu K, young Oh T. Effects of visual information on joint angular velocity of trunk and lower extremities in sitting and squat motion. J Kor Phys Ther. 2015;27(2):89-95.

11. Im IS. The effect of ocular pursuit training on ice-hockey player's dynamic visual acuity (DVA) and performance. Kor Soc Exer Physiol. 2003;12(2):287-96.

12. Stoffregen TA, Bardy BG, Bonnet CT et al. Postural stabilization of visually guided eye movements. Ecol Psychol. 2006;18(3):191-222.

13. Aguiar SA, Polastri PF, Godoi D et al. Effects of saccadic eye movements on postural control in older adults. Psychol Neurosci. 2015;8(1):19.

14. Ajrezo L, Wiener-Vacher S, Bucci MP. Saccades improve postural control: A developmental study in normal children. PloS one. 2013;8(11): e81066.

15. Rougier P, Garin M. Performing saccadic eye movements or blinking improves postural control. Motor Control. 2007;11(3):213-23.

16. Guerraz M, Bronstein AM. Ocular versus extraocular control of posture and equilibrium. Neurophysiol Clin. 2008;38(6):391-8.

17. Hotson JR. Gary WS. Vertical and horizontal saccades in aging and dementia: failure to inhibit anticipatory saccades. Neuro-ophthalmology. 1988;8(5):267-73.

18. Lajoie Y, Teasdale N, Bard C et al. Attentional demands for static and dynamic equilibrium. Exp Brain Res. 1993;97(1):139-44.

19. Corbetta M, Akbudak E, Conturo TE et al. A common network of functional areas for attention and eye movements. Neuron. 1998;21(4):76173.

20. Hoffman JE, Subramaniam B. The role of visual attention in saccadic eye movements. Percept Psychophys. 1995;57(6):787-95.

21. Ham SC, Lim CG. The effects of robot-assisted gait training with visual feedback on gait, balance and balance confidence in chronic stroke patients. J Kor Phys Ther. 2016;28(2):71-6.

22. Hyndman D, Ashburn A. People with stroke living in the community: Attention deficits, balance, adl ability and falls. Disabil Rehabil. 2003; 25(15):817-22. 
23. Huxhold O, Li S-C, Schmiedek F et al. Dual-tasking postural control: Aging and the effects of cognitive demand in conjunction with focus of attention. Brain Res Bull. 2006;69(3):294-305.

24. Owsley C, McGwin G. Association between visual attention and mobility in older adults. J Am Geriatri Soc. 2004;52(11):1901-6.

25. Rodrigues ST, Polastri PF, Carvalho JC et al. Saccadic and smooth pursuit eye movements attenuate postural sway similarly. Neurosci lett. 2015;584:292-5.
26. Seo SK, Kim SH, Kim TY. Evaluation of static balance in postural tasks and visual cue in normal subjects. J Kor Phys Ther. 2009;21(4):59-63.156.

27. Kavounoudias A, Roll R, Roll JP. Foot sole and ankle muscle inputs contribute jointly to human erect posture regulation. J Physiol. 2001;532(3): 869-78.

28. Chae YW, Park JW, Park S. Effects of knee malalignment on static and dynamic postural stability. J Kor Phys Ther. 2015;27(1):7-11. 